Check for updates

Cite this: RSC Adv., 2019, 9, 18196

Received 22nd April 2019

Accepted 22nd May 2019

DOI: $10.1039 / c 9 r a 02988 e$

rsc.li/rsc-advances

\section{Nanoscale iron (oxyhydr)oxide-modified carbon nanotube filter for rapid and effective $\mathrm{Sb}(\mathrm{III})$ removal $\uparrow$}

\author{
Yanbiao Liu, (D) *ab Jinyu Yao, ${ }^{a}$ Fuqiang Liu, ${ }^{a}$ Chensi Shen, ${ }^{\text {ab }}$ Fang Li, ${ }^{\text {ab }}$ Bo Yang, ${ }^{\text {*a }}$ \\ Manhong Huang ${ }^{\mathrm{ab}}$ and Wolfgang Sand ${ }^{\mathrm{ac}}$
}

\begin{abstract}
Herein, nanoscale iron (oxyhydr)oxide-coated carbon nanotube (CNT) filters were rationally designed for rapid and effective removal of $\mathrm{Sb}(\mathrm{III})$ from water. These iron (oxyhydr)oxide particles $(<5 \mathrm{~nm})$ were uniformly coated onto the CNT sidewalls. The as-fabricated hybrid filter demonstrated improved sorption kinetics and capacity compared with the conventional batch system. At a flow rate of 6 $\mathrm{mL} \mathrm{min}{ }^{-1}$, a Sb(III) pseudo-first-order adsorption rate constant of 0.051 and a removal efficiency of $>99 \%$ was obtained when operated in the recirculation mode. The improved Sb(III) sorption performance can be ascribed to the synergistic effects of convection-enhanced mass transport, limited pore size, and more exposed active sorption sites of the filters. The presence of 1-10 mmol $\mathrm{L}^{-1}$ of carbonate, sulfate, and chloride inhibits $\mathrm{Sb}(\mathrm{III})$ removal negligibly. Exhausted hybrid filters can be effectively regenerated by an electrical field-assisted chemical washing method. STEM characterization confirmed that Sb was mainly sequestered by iron (oxyhydr)oxides. XPS, AFS and XAFS results suggest that a certain amount of $\mathrm{Sb}(\mathrm{III})$ was converted to $\mathrm{Sb}(\mathrm{V})$ during filtration. DFT calculations further indicate that the bonding energy for $\mathrm{Sb}(\mathrm{III})$ onto the iron (oxyhydr)oxides was $2.27-2.30 \mathrm{eV}$, and the adsorbed $\mathrm{Sb}(\mathrm{III})$ tends to be oxidized.
\end{abstract}

\section{Introduction}

Recently, increased water contamination caused by the emerging contaminant antimony ( $\mathrm{Sb}$ ) has raised global concern. ${ }^{1-3}$ Anthropogenic activities such as manufacturing, mining and smelting are the main reasons for $\mathrm{Sb}$ contamination. For example, it has been previously reported that the total $\mathrm{Sb}$ concentration close to the field sites of the Xikuangshan area (Hunan, China) ranged from 2 to $6384 \mu \mathrm{g} \mathrm{L}^{-1} \cdot{ }^{4,5}$ As a metalloid element, $\mathrm{Sb}$ is located in group 15 (VA) of the periodic table, structurally analogous to arsenic, but much less attention has been given to $\mathrm{Sb}$ removal when compared with arsenic., Generally, the most common aqueous $\mathrm{Sb}$ species are inorganic $\mathrm{Sb}(\mathrm{OH})^{6-}$ and $\mathrm{Sb}(\mathrm{OH})_{3},{ }^{8}$ and $\mathrm{Sb}(\mathrm{III})$ is 10 times more toxic than $\mathrm{Sb}(\mathrm{v})$. Because of its negative impact on human life, the World Health Organization has set the permissible amount of total $\mathrm{Sb}$ in drinking water at $5 \mu \mathrm{g} \mathrm{\textrm {L } ^ { - 1 }}$.

${ }^{a}$ Textile Pollution Controlling Engineering Center of Ministry of Environmental Protection, College of Environmental Science and Engineering, Donghua University, 2999 North Renmin Road, Shanghai 201620, PR China. E-mail: yanbiaoliu@dhu. edu.cn; yangbo@dhu.edu.cn; Tel: +862167798752

${ }^{b}$ Shanghai Institute of Pollution Control and Ecological Security, 1239 Siping Road, Shanghai 200092, PR China

${ }^{c}$ Institute of Biosciences, Freiberg University of Mining and Technology, Freiberg 09599, Germany

$\dagger$ Electronic supplementary information (ESI) available. See DOI: 10.1039/c9ra02988e
Various Sb treatment technologies, including adsorption, ${ }^{\mathbf{9 , 1 0}}$ coagulation, ${ }^{\mathbf{1 1}}$ flocculation, ${ }^{\mathbf{1 2}}$ and membrane filtration, ${ }^{13}$ have been developed to remove $\mathrm{Sb}$ from water bodies. Among these, sorption is a widely applied and promising technique due to its limited energy requirement, high performance, costeffectiveness, and ease of operation. Recently, various nanoscale sorbents with large surface area and $\mathrm{Sb}$ specificity have been exploited. ${ }^{\mathbf{1 4 - 1 6}}$ For example, nanoscale iron-based materials have demonstrated enhanced performance towards $\mathrm{Sb}$ removal, ${ }^{17}$ owing to their chemical affinity and high adsorption capacity. Extended X-ray absorption fine structure (EXAFS) spectroscopy indicated that $\mathrm{Sb}$ (III) and $\mathrm{Sb}(\mathrm{v})$ adsorbed at the hydrous ferric oxide surface as an inner-sphere complex with an average $\mathrm{Sb}-\mathrm{Fe}$ distance of $3.02 \AA$ and $3.19 \AA$, respectively. ${ }^{18}$

However, despite the progress made on $\mathrm{Sb}$ adsorption capacity, the adsorption kinetics is still far from satisfaction. This can be explained by the poor driving force and relatively low concentrations detected in water. The time needed to reach equilibrium is usually several hours (e.g., $>28 \mathrm{~h}$ for the chitosan-iron(III) composite) $)^{19}$ or even a few days (e.g., 7 days for goethite). ${ }^{20}$ Furthermore, nanomaterial is not reliable for direct application in the removal of $\mathrm{Sb}$, as it is hindered by postseparation and reutilization. To address these problems, these sorbents can either be coated on macroscopic supporting materials or immobilized into the membrane. However, these designs usually achieve limited success due to inevitable blocking of active sorption sites of the nanoscale sorbents. 
A carbon nanotube (CNT) filter coated with nanoscale iron (oxyhydr)oxides may provide a feasible solution to address these limitations. ${ }^{21}$ CNT can be readily assembled into a $3 \mathrm{D}$ selfsupport membrane by vacuum filtration. ${ }^{22}$ The network of CNT filters with large specific surface areas and limited pore size provides an ideal scaffold for nanoscale iron (oxyhydr) oxides. Improved Sb sorption kinetics and enhanced sorption capacity can be expected because of the synergistic effects of small pore size and more exposed sorption sites of the iron (oxyhydr)oxide/CNT network, as well as the flow-through design.

The aim of the present study is to develop an iron (oxyhydr) oxide/CNT hybrid filter for simultaneous adsorption and detoxification of $\mathrm{Sb}$ (III). To do this, we firstly developed a facile filtration route to prepare a binder-free iron (oxyhydr)oxidecoated CNT filter with more exposed active sites. Various advanced characterization techniques were employed to obtain detailed physicochemical characteristics of the iron (oxyhydr) oxide/CNT filter. $\mathrm{Sb}$ (III) sorption kinetics were experimentally and theoretically examined. The impact of several key operational parameters on $\mathrm{Sb}$ sequestration performance were examined and optimized. Sb-spiked tap water was used to challenge the iron (oxyhydr)oxide/CNT filter to evaluate its potential for use in practical engineering applications. This study provides new insights for the rational design of a continuous flow system for the decontamination of $\mathrm{Sb}$ and other similar heavy-metal ions.

\section{Materials and methods}

\subsection{Chemicals and materials}

$N$-Methyl-2-pyrrolidinone (NMP, $\geq 99.5 \%$ ), iron trichloride hexahydrate $\left(\mathrm{FeCl}_{3} \cdot 6 \mathrm{H}_{2} \mathrm{O}, \geq 99 \%\right)$, hydrochloric acid ( $\mathrm{HCl}, 36-$ $38 \%$ ), sodium hydroxide $(\mathrm{NaOH}, \geq 96 \%)$, nitric acid $\left(\mathrm{HNO}_{3}, 36-\right.$ $38 \%$ ), and ethanol ( $\geq 96 \%$ ) were purchased from Sinopharm Chemical Reagent Co., Ltd. (China). Sodium borohydride $\left(\mathrm{NaBH}_{4}, \geq 98 \%\right), \mathrm{C}_{8} \mathrm{H}_{4} \mathrm{~K}_{2} \mathrm{O}_{12} \mathrm{Sb}_{2} \cdot 3 \mathrm{H}_{2} \mathrm{O}$ and $\mathrm{KSb}(\mathrm{OH})_{6}$ were purchased from Sigma-Aldrich. Multi-walled carbon nanotubes (MWCNTs, $\langle d\rangle=10-20 \mathrm{~nm}$ ) were purchased from TimesNano Co., Ltd. (ChengDu, China). PTFE membranes $(\langle d\rangle=47 \mathrm{~mm})$ were purchased from Millipore (Omnipore JWMP; Millipore). All aqueous solutions were prepared with ultra-pure water from a Milli-Q Direct 8 purification system.

\subsection{Fabrication of iron (oxyhydr)oxide/CNT filter}

The CNT was pre-treated with concentrated $\mathrm{HNO}_{3}$ at $70{ }^{\circ} \mathrm{C}$ for $12 \mathrm{~h}$ to generate surface carboxylates $\left(\mathrm{CNT}-\mathrm{COO}^{-}\right)$for $\mathrm{Fe}^{3+}$ chelation..$^{23}$ First, $20 \mathrm{mg}$ of $\mathrm{CNT}^{-\mathrm{COO}^{-}}$powder was dispersed in $30 \mathrm{~mL}$ of NMP under probe-sonication for $30 \mathrm{~min}$, followed by the addition of $10 \mathrm{~mL}$ of ethanol solution doped with $15 \mathrm{mg}$ of $\mathrm{FeCl}_{3} \cdot 6 \mathrm{H}_{2} \mathrm{O}$. Then, the mixture solution was bath-sonicated for $20 \mathrm{~min}$ to allow $\left[\mathrm{Fe}^{3+}\right]$ to chelate with the carboxylic groups of CNT. Further, $0.5 \mathrm{~mL}$ of $0.75 \mathrm{~mol} \mathrm{~L}^{-1} \mathrm{NaBH}_{4}$ solution was added dropwise to transform the loaded $\left[\mathrm{Fe}^{3+}\right]$ to nanoscale iron (oxyhydr)oxide in situ. The mixture was loaded onto a hydrophilic PTFE membrane via vacuum filtration and washed sequentially with $100 \mathrm{~mL}$ of ethanol and $200 \mathrm{~mL}$ of ultra-pure water. Finally, the as-obtained iron (oxyhydr)oxide/CNT filter was preserved in deionized water for sorption experiment or dried in a vacuum freeze dryer for further characterization.

\subsection{Sb sorption experiments}

Three modes were used to comparatively evaluate $\mathrm{Sb}$ (III) adsorption: recirculated filtration, single-pass filtration, and batch analysis. For the batch system, the as-fabricated iron (oxyhydr)oxide/CNT filter was put in a flask containing $100 \mathrm{~mL}$ of $900 \mu \mathrm{g} \mathrm{L}^{-1} \mathrm{Sb}$ (III) solution at $\mathrm{pH}$ 7. The flask was sealed and put into a shaker at $25^{\circ} \mathrm{C}$ and $150 \mathrm{rpm}$ for $6 \mathrm{~h}$. For recirculated filtration, the hybrid filter was placed in a commercial Whatman polycarbonate filtration casing (Fig. S1†). $100 \mathrm{~mL}$ of $\mathrm{Sb}$ (III) solution was pumped through an iron (oxyhydr)oxide/CNT filter and then returned. To examine Sb sorption kinetics, recirculated filtration was completed with a flow rate of 1.5, 3 and 6

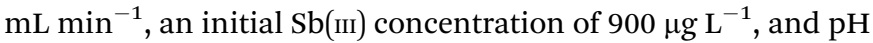
7. For single-pass filtration, 100 or $200 \mu \mathrm{g} \mathrm{L}^{-1}$ of $\mathrm{Sb}$ (III) solution was pumped at a fixed flow rate of $1.5 \mathrm{~mL} \mathrm{~min}{ }^{-1}$ through an iron (oxyhydr)oxide/CNT filter at pH 7 until the effluent was no longer returned. The filter bed volume was $0.113 \mathrm{~mL}$ and the empty bed contact time (EBCT) was $4.5 \mathrm{~s}$. The method of singlepass filtration bed volume calculation can be found in the ESI. $\dagger$ Aliquots were sampled at specific time intervals to investigate the sorption kinetics. The $\mathrm{Sb}$ concentration was determined using a Thermo Scientific iCAP-Q inductively coupled plasma mass spectrometer (ICP-MS, Waltham, MA).

To evaluate the effect of $\mathrm{pH}$ on $\mathrm{Sb}$ (III) adsorption, the solution $\mathrm{pH}$ was adjusted from 3 to 9 using $0.1 \mathrm{~mol} \mathrm{~L}^{-1} \mathrm{HNO}_{3}$ or $0.1 \mathrm{~mol} \mathrm{~L}^{-1} \mathrm{NaOH}$. The experiments were completed in the recirculation mode using $100 \mathrm{~mL}$ of $900 \mu \mathrm{g} \mathrm{L}^{-1}$ reservoir. To investigate the effects of coexisting anions, 1 to $10 \mathrm{mmol} \mathrm{L}^{-1}$ of chloride, carbonate, silicate, sulfate and phosphate were added to the $\mathrm{Sb}$ (III) solution before passing through the iron (oxyhydr) oxide/CNT filter and operated in the recirculation mode. The exhausted iron (oxyhydr)oxide/CNT filters were regenerated either by passing $100 \mathrm{~mL}$ of $5 \mathrm{mmol} \mathrm{L}^{-1} \mathrm{NaOH}$ through it or by applying a negative total cell potential of $-2 \mathrm{~V}$ while passing through $100 \mathrm{~mL}$ of $10 \mathrm{mmol} \mathrm{L}^{-1} \mathrm{Na}_{2} \mathrm{SO}_{4}$ and $5 \mathrm{mmol} \mathrm{L}^{-1} \mathrm{NaOH}$ solution.

\subsection{Characterizations}

The morphology of the filters was examined on a Hitachi S-4800 field emission scanning electron microscope (FESEM, Japan), a JEM-2100F transmission electron microscope (TEM, Japan), and an ARM200F scanning transmission electron microscope (STEM, Japan). The STEM was equipped with a high-angle annular dark field detector and a spherical aberration correction system. X-ray photoelectron spectroscopy (XPS) was completed on a Thermo Fisher Scientific Escalab 250Xi under high vacuum $\left(1 \times 10^{-9}\right.$ torr $)$, and all binding energies were calibrated and referenced to the $\mathrm{C} 1 \mathrm{~s}$ peak at $284.8 \mathrm{eV}$. The crystal structure of the filters was analyzed using a Rigaku D/ max-2550 PC X-ray diffraction (XRD) analysis. The BrunauerEmmett-Teller (BET) surface area of the filters was examined on 
a Quantachrome Autosorb iQ-c analyzer. The water contact angle was measured with a Kino SL200KS Optical contact angle $\&$ interface tension meter.

XAFS was measured at the XAFS station (beamlines BL14W1) of the Shanghai Synchrotron Irradiation Facility (SSRF) with a stored electron energy of $3.5 \mathrm{GeV}$ and ring currents of 200 $\mathrm{mA} .^{24}$ Because of the small nominal concentration of $\mathrm{Sb}$ in the samples, data were collected in the fluorescence mode. Data processing was performed with the use of the IFEFFIT software package. ${ }^{25}$ The EXAFS function, $\chi$, was obtained by subtracting the post-edge background from the overall absorption and was later normalized with respect to the edge jump step.

\subsection{Theoretical sorption analysis by DFT}

The sequestration of $\mathrm{Sb}(\mathrm{III})$ or $\mathrm{Sb}(\mathrm{v})$ was performed by DFT calculations using the CP2K package. ${ }^{26}$ The model building process and instructions are detailed in the ESI. $\dagger$

\section{Results and discussion}

\subsection{Characterizations of iron (oxyhydr)oxide/CNT filters}

Fig. 1 displays the FESEM and TEM characterizations of the CNT and iron (oxyhydr)oxide/CNT filter, respectively. The CNT network showed a smooth surface with a tube diameter of $22 \pm$ $7 \mathrm{~nm}$, while the iron (oxyhydr)oxide/CNT network produced a much rougher surface with an increased tube diameter of $25 \pm$ $6 \mathrm{~nm}$. It can be seen that a thin layer of nanoscale iron (oxyhydr) oxide $(<5 \mathrm{~nm})$ was uniformly coated onto the surface of the CNTs. Similar XRD patterns of the filter samples were obtained regardless of the iron (oxyhydr)oxide coating, possibly due to the limited loading amount of iron (oxyhydr)oxide (Fig. S2 $\dagger$ ). Thermogravimetric analysis (TGA) results suggested that the asfabricated iron (oxyhydr)oxide/CNT filter contained $20 \mathrm{mg}$ (88.9\%) of CNTs and $2.5 \pm 0.5 \mathrm{mg}(11.9 \%)$ of iron (oxyhydr)oxide (Fig. S3†), and the filter diameter was $40 \mathrm{~mm}$; only $1.4 \pm 0.3 \mathrm{mg}$ of iron (oxyhydr)oxide was available after placing in the filtration casing with an effective filtration diameter of $30 \mathrm{~mm}$. Limiting the amount of iron (oxyhydr)oxide led to only a slight increase in the Brunauer-Emmett-Teller (BET) specific surface area after iron (oxyhydr)oxide loading $\left(174.2 \mathrm{~m}^{2} \mathrm{~g}^{-1}\right.$ vs. $170.4 \mathrm{~m}^{2}$ $\left.\mathrm{g}^{-1}\right)$. Meanwhile, the filter hydrophilicity was slightly improved after the iron (oxyhydr)oxide coating, as manifested by the decreased water contact angle from $111^{\circ}$ (before loading) to $101^{\circ}$ (after loading) (Fig. S4 $\dagger$ ). XPS analyses also confirmed the successful coating of iron (oxyhydr)oxide onto the CNT sidewalls (Fig. S5 $\dagger$ ). While the CNT filter showed a superficial elemental atomic ratio of $98.5 \% \mathrm{C}$ and $1.5 \% \mathrm{O}$, that of the iron (oxyhydr)oxide/CNT filter was 91.3\% C, 6.8\% O, and 1.9\% Fe. All these evidences suggest the successful fabrication of the iron (oxyhydr)oxide/CNT hybrid filter.

\section{2 $\mathrm{Sb}(\mathrm{III})$ sorption kinetics}

The impact of the operation mode (batch $v s$. filtration), flow rate $\left(1.5,3\right.$, and $\left.6 \mathrm{~mL} \mathrm{~min}^{-1}\right)$, and $\mathrm{pH}(3,5,7$ and 9) on the overall $\mathrm{Sb}$ (III) sequestration kinetics were further evaluated. A control experiment on $\mathrm{Sb}(\mathrm{III})$ sorption by a CNT-alone filter only exhibited negligible sorption (Fig. S6†), suggesting that CNTs did not have a specific affinity to $\mathrm{Sb}(\mathrm{III})$. $\mathrm{Sb}(\mathrm{III})$ sorption kinetics
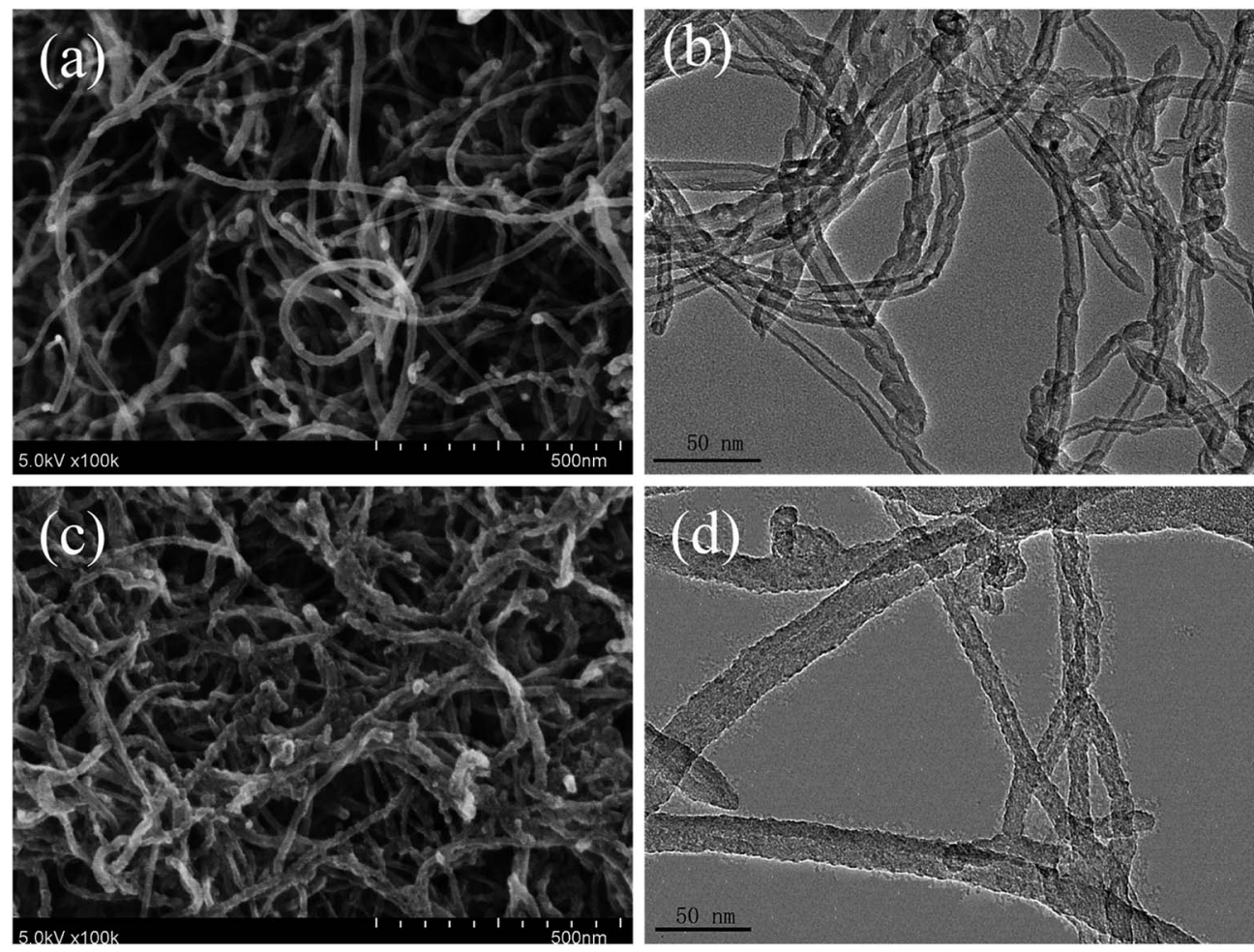

Fig. 1 FESEM and TEM images of plain CNT ( $a$ and b) and the iron (oxyhydr)oxide/CNT (c and d) filter. 
of the iron (oxyhydr)oxide/CNT filter were systematically studied and summarized in Fig. 2a. To quantitatively demonstrate the $\mathrm{Sb}$ (III) sorption kinetics, experimental data were fitted by the pseudo-first-order model, as given in eqn (1) and (2). The corresponding parameters were available in Table 1.

$$
\begin{aligned}
& \ln \left(\frac{q_{\mathrm{e}}-q_{t}}{q_{\mathrm{e}}}\right)=k t \\
& q_{t}=q_{\mathrm{e}}\left(1-\mathrm{e}^{-k t}\right)
\end{aligned}
$$

where $q_{t}$ represents the amount adsorbed at time $t(\min ), q_{\mathrm{e}}$ is the amount adsorbed at equilibrium, and $k$ is the pseudo-firstorder adsorption rate constant (inverse min). A $q_{\mathrm{e}}$ value of $5.28 \mathrm{mg} \mathrm{g}^{-1}$ and a $k$ of $0.0052 \mathrm{~s}^{-1}$ was obtained in the conventional batch mode over $6 \mathrm{~h}$, while both $q_{\mathrm{e}}$ and $k$ increased significantly in the recirculated filtration. As shown in Fig. 2a, the $\mathrm{Sb}$ (III) sorption kinetics increased with the flow rate, indicating that filter adsorption is the rate-determining step. At flow rates of $1.5,3$, and $6 \mathrm{~mL} \mathrm{~min}^{-1}$, the $q_{\mathrm{e}}$ values were $6.68,7.01$ and $7.06 \mathrm{mg} \mathrm{g}^{-1}$ with $k$ values of $0.018,0.028$ and $0.051 \mathrm{~min}^{-1}$, respectively. Meanwhile, the corresponding equilibrium times also decreased from $>4 \mathrm{~h}$ to $1.5 \mathrm{~h}$ when the flow rate increased

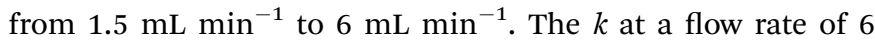
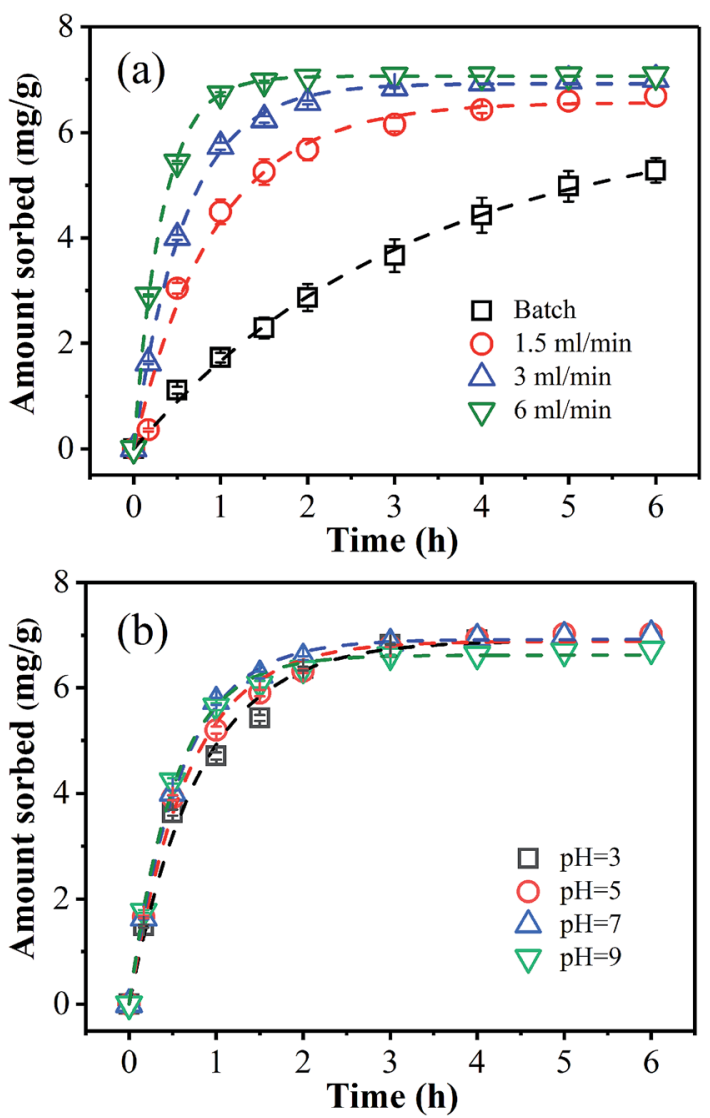

Fig. 2 (a) Sorption kinetics of $\mathrm{Sb}($ (II) adsorption by the iron (oxyhydr) oxides/CNT filter. Comparison of the batch mode (blank) and the recirculation mode with various flow rates of 1.5 (red), 3 (blue), and 6 $\mathrm{mL} \mathrm{min}^{-1}$ (green); (b) effect of $\mathrm{pH}(3,5,7,9)$ on $\mathrm{Sb}($ (II) sorption.
Table 1 Kinetics parameters of pseudo-first-order Sb(III) sorption

\begin{tabular}{llll}
\hline & $k\left(\mathrm{~min}^{-1}\right)$ & $q_{\mathrm{e}}\left(\mathrm{mg} \mathrm{g}^{-1}\right)$ & $R^{2}$ \\
\hline Batch & 0.0052 & 5.28 & 0.997 \\
1.5 & 0.018 & 6.68 & 0.986 \\
3 & 0.028 & 7.01 & 0.998 \\
6 & 0.051 & 7.06 & 0.999
\end{tabular}

$\mathrm{mL} \min ^{-1}$ was $\sim 10$ times higher than that of the batch mode. For $\mathrm{Sb}$ removal efficiency, the batch mode only removed $75 \%$ of the initial $\mathrm{Sb}(\mathrm{III})$ and did not reach equilibrium after $6 \mathrm{~h}$. When the flow rate increased from $1.5 \mathrm{~mL} \mathrm{~min}{ }^{-1}$ to $6 \mathrm{~mL} \mathrm{~min}^{-1}$, the corresponding removal efficiency increased from $94 \%$ to $>99 \%$ (Fig. S7 $\dagger$ ). This can be explained by the convection-enhanced mass transport of the flow-through system, while the conventional batch reactor depends on diffusion-controlled mass transport. Besides, the small pore size in the iron (oxyhydr) oxide/CNT network $(<80 \mathrm{~nm}$ ) also enhanced the adsorption of $\mathrm{Sb}$ by the hybrid filter. Fig. 2b shows that the iron (oxyhydr) oxide/CNT filter worked effectively across a wide $\mathrm{pH}$ range. This is because the $\mathrm{Sb}$ (III) species (i.e., $\mathrm{Sb}(\mathrm{OH})_{3}$ ) in the aqueous solution remain unchanged from $\mathrm{pH} 3$ to $10 .^{27}$

\subsection{Sorption isotherms}

$\mathrm{Sb}$ (III) sorption isotherms on the iron (oxyhydr)oxide/CNT filter were conducted in the recirculation mode and fitted with the Freundlich isotherm model as given in eqn (3):

$$
q_{\mathrm{e}}=K_{\mathrm{f}} C_{\mathrm{e}}{ }^{1 / n}
$$

where $q_{\mathrm{e}}$ is the $\mathrm{Sb}$ amount sorbed by the iron (oxyhydr)oxide/ CNT filter at equilibrium, $C_{\mathrm{e}}$ is the equilibrium concentration, while $K_{\mathrm{f}}$ and $n$ are constants, respectively, related to adsorption capacity and intensity. Fitting results suggest that the data fit the Freundlich model well with a correlation coefficient of 0.991 (Fig. S8 $\dagger$ ). For $\mathrm{Sb}($ III), the iron (oxyhydr)oxide/CNT filter maximum adsorption capacity reached $44.22 \mathrm{mg} \mathrm{g}^{-1}\left(C_{\mathrm{e}}=1307\right.$ $\left.\mu \mathrm{g} \mathrm{L}^{-1}\right)$. The actual maximum sorption capacity could be even greater as the value of $q_{\mathrm{e}}$ did not reach a plateau. The ascalculated $K_{\mathrm{f}}$ and $n$ were 2.17 and 2.4, respectively. Note that the $\mathrm{Sb}(\mathrm{III})$ adsorption capacity of iron (oxyhydr)oxide/CNT filters are comparable with powdered or granular iron oxyhydroxides ${ }^{18,20}$ and other iron-based sorbents. ${ }^{10,28}$ The improved performance can be attributed to convection-enhanced mass transport in the flow-through design, smaller pore size, and improved availability of the sorption sites of the iron (oxyhydr) oxide/CNT filters.

\subsection{STEM and XPS analyses}

We further conducted scanning transmission electron microscopy (STEM) to demonstrate Sb sequestration. Fig. 3 and S9† present the high-angle annular dark-field (HAADF) images and elemental mapping of an Sb-loaded iron (oxyhydr)oxide/CNT filter. As shown from the mapping results of $\mathrm{Fe}$ and $\mathrm{C}$, these iron (oxyhydr)oxide particles were uniformly coated onto the 


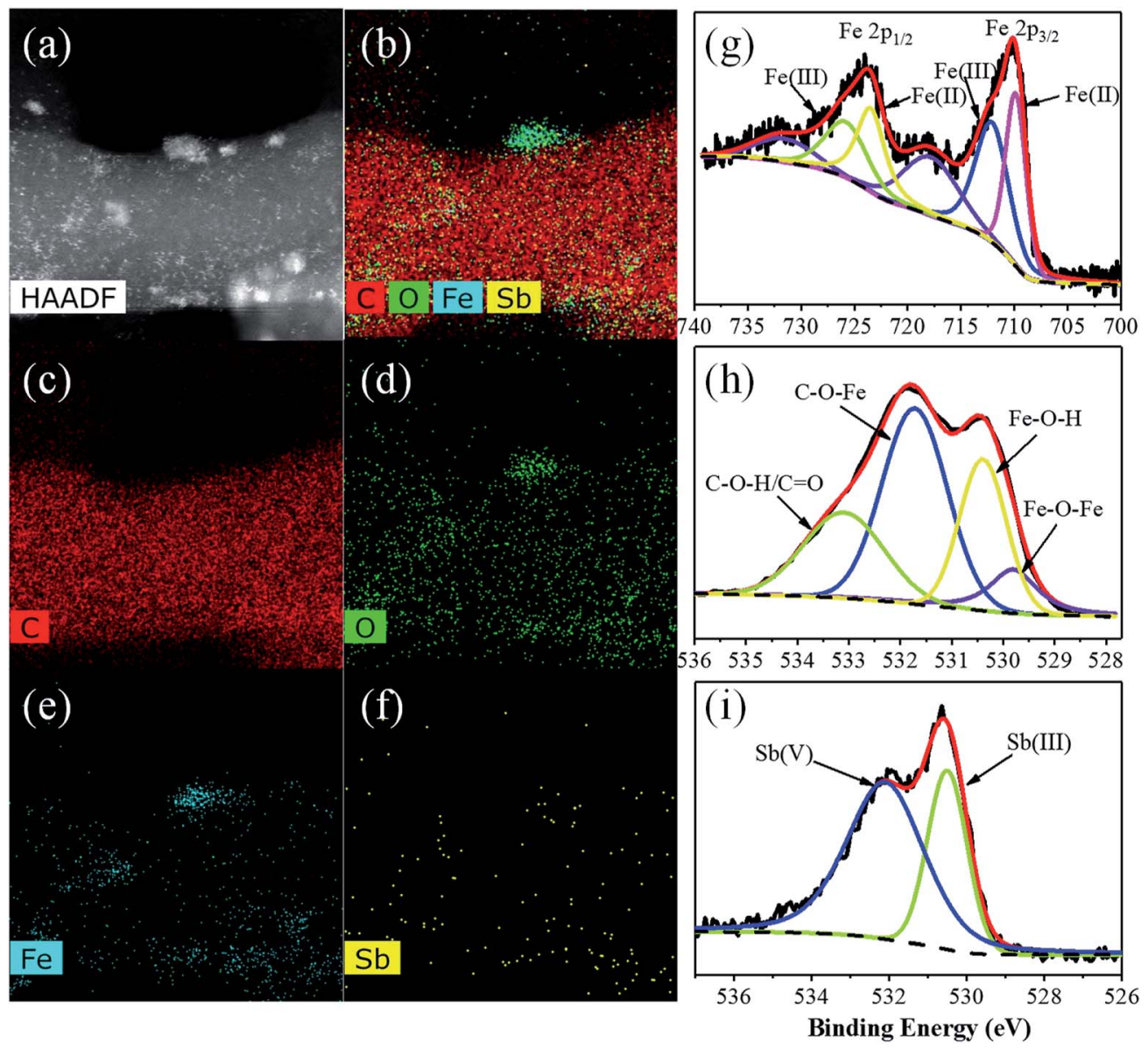

Fig. 3 HAADF image (a) of the Sb-loaded iron (oxyhydr)oxides/CNT filter and the corresponding EDS elemental mapping: (b) $\mathrm{C}+\mathrm{O}+\mathrm{Sb}+\mathrm{Fe}$, (c) $\mathrm{C}$, (d) O, (e) Fe, (f) Sb; and (g) XPS Fe 2p spectra, (h) XPS O 1s spectra of the fresh iron (oxyhydr)oxides/CNT filter and (i) XPS Sb 3d spectra of the Sbloaded iron (oxyhydr)oxides/CNT filter.

CNT sidewalls. This result was consistent with TEM characterizations. In addition, the elemental distribution of $\mathrm{Sb}$ was consistent with that of $\mathrm{Fe}$ (or O), suggesting that $\mathrm{Sb}$ was mainly sequestered by the coated iron (oxyhydr)oxide.

XPS was performed to further examine the elemental composition of the iron (oxyhydr)oxides/CNT filter before and after Sb sorption. As shown in Fig. S5, $\dagger$ the XPS survey pattern of a fresh iron (oxyhydr)oxides/CNT filter confirmed the presence of $\mathrm{C}$ 1s, O 1s, Fe 2s, Fe 2p, and Fe 3p, while an Sb 3d characteristic peak was identified on an Sb-loaded filter sample. A high-resolution scan of Fe 2 p over a small window is presented in Fig. 3g. The characteristic peaks centred at 710 and $712 \mathrm{eV}$ can be assigned to Fe(II) and Fe(III), respectively. Furthermore, as shown in Fig. 3h, the $\mathrm{O}$ 1s spectrum can be deconvoluted into four peaks, assigned to the oxygen from hydroxyl, ether and carbonyl (533.1 eV), Fe-O-H (531.8 eV), Fe-O-C (531.2 eV), and $\mathrm{Fe}-\mathrm{O}-\mathrm{Fe}(530.2 \mathrm{eV})$, respectively. The presence of surface $\mathrm{Fe}-\mathrm{O}-$ $\mathrm{H}$ confirmed the species of $\mathrm{FeOOH}$, and $\mathrm{Fe}-\mathrm{O}-\mathrm{Fe}$ may be attributed to species of $\mathrm{FeOOH}$ and $\mathrm{Fe}_{2} \mathrm{O}_{3}$. It should be mentioned that $\mathrm{Fe}-\mathrm{O}-\mathrm{C}$ is the largest constituent of surface $\mathrm{O}$ atoms, indicating the strong interaction between iron particles and the CNT network support. The XPS results of O 1s indicate that the iron (oxyhydr)oxides were mainly composed of $\mathrm{FeOOH}$ and $\mathrm{Fe}_{2} \mathrm{O}_{3}$. In comparison, the characteristic peak of $\mathrm{Sb} 3 \mathrm{~d}$ appeared on an Sb-loaded iron (oxyhydr)oxides/filter (Fig. 3i). Further fitting the $\mathrm{Sb} 3 \mathrm{~d}$ spectrum suggested that certain $\mathrm{Sb}$ (III) were converted to $\mathrm{Sb}(\mathrm{v})$, as supported by the co-existence of $\mathrm{Sb}(\mathrm{III})$, centred at $530.2 \mathrm{eV}$, and $\mathrm{Sb}(\mathrm{v})$, centred at $532.3 \mathrm{eV}$. The transformation of $\mathrm{Sb}(\mathrm{III})$ to $\mathrm{Sb}(\mathrm{v})$ may be due to oxidation by these surficial iron oxides. Detailed explanations will be provided in the DFT calculation section.

The conversion of $\mathrm{Sb}(\mathrm{III})$ to $\mathrm{Sb}(\mathrm{v})$ was further supported by the determination of effluent $\mathrm{Sb}$ species by atomic fluorescence spectrometry (AFS). As presented in Fig. $4 \mathrm{a}$, both $\mathrm{Sb}_{\text {total }}$ and $\mathrm{Sb}$ (III) decreased exponentially with time. Only negligible $\mathrm{Sb}(\mathrm{v})$ was detected in the effluent within the initial $2 \mathrm{~h}$, while its concentration increased linearly afterwards. The change in $\mathrm{Sb}$ species suggests that the continuous-flow filter enables simultaneous sequestration and oxidization of $\mathrm{Sb}(\mathrm{III})$. This result is in good accordance with the XPS characterization of the used filter sample. More solid evidence could be obtained from the XAFS characterization, which provides essential information on the valence states of the adsorbed Sb species. Fig. $4 \mathrm{~b}$ presents $\mathrm{Sb}$ K-edge XANES spectra of an exhausted 

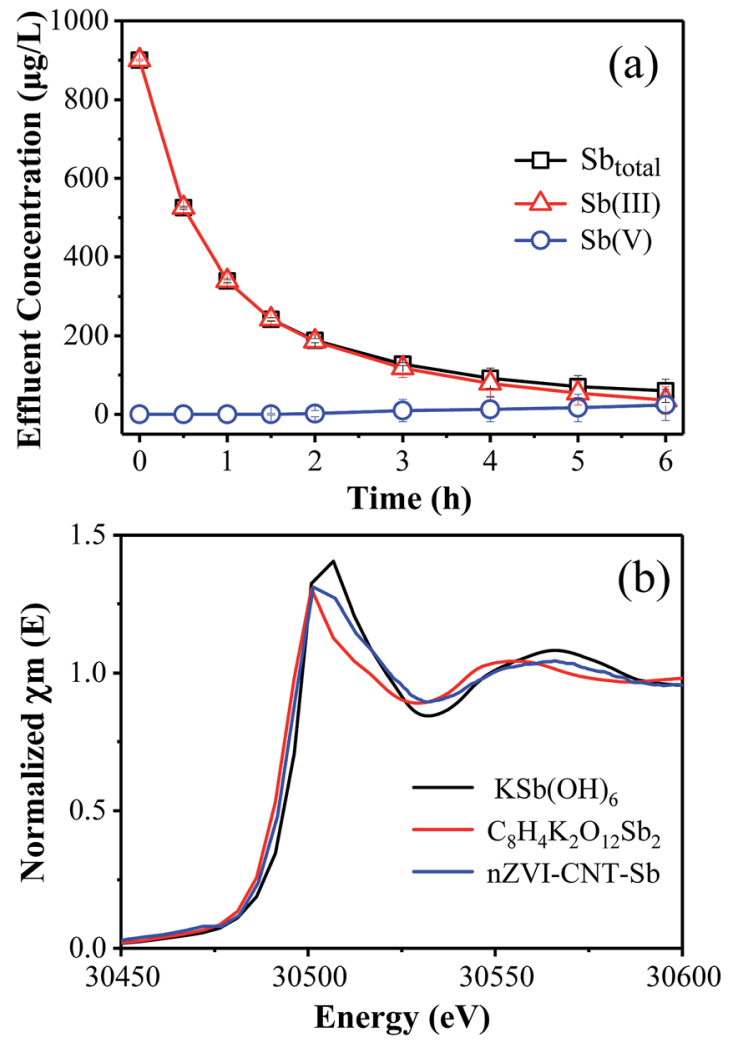

Fig. 4 (a) Changes in the concentration $\mathrm{Sb}_{\text {total }}$ and Sb species as a function of time as determined by AFS. (b) Sb K-edge XANES spectra for the Sb-adsorbed iron (oxyhydr)oxides/CNT filter.

iron (oxyhydr)oxide/CNT filter sample. This technique provides solid evidences on the oxidation state of $\mathrm{Sb}$, as indicated by the energy of the adsorption edge. Generally, the edge energy increases with an increase in the oxidation state. ${ }^{29}$ Comparing the Sb XANES spectra of the $\mathrm{Sb}$ (III)-loaded filter with those of the reference compounds (i.e., $\mathrm{KSb}(\mathrm{OH})_{6}$ and $\mathrm{C}_{8} \mathrm{H}_{4} \mathrm{~K}_{2} \mathrm{O}_{12} \mathrm{Sb}_{2}$ were used as references for $\mathrm{Sb}(\mathrm{v})$ and $\mathrm{Sb}(\mathrm{III})$, respectively), indicated that $\mathrm{Sb}$ was present in the valence states of $\mathrm{Sb}(\mathrm{v})$ and $\mathrm{Sb}(\mathrm{III})$.

\subsection{Effect of solution chemistry}

Fig. 5 a shows the effect of the selected co-existing anions on $\mathrm{Sb}$ (III) removal. The results suggest that the presence of 1$10 \mathrm{mmol} \mathrm{L}^{-1}$ of carbonate, sulphate, and chloride showed negligible inhibition of $\mathrm{Sb}$ (III) removal. This can be explained by the different sorption mechanisms of $\mathrm{Sb}$ and these co-existing anions. $\mathrm{Sb}$ (III) was chemisorbed onto iron (oxyhydr)oxide particles via the formation of an innersphere complex, ${ }^{17}$ while carbonate, sulphate, and chloride were adsorbed by an alternative manner of electrostatic attraction. Contrarily, the presence of phosphate and silicate reduced $\mathrm{Sb}(\mathrm{III})$ removal efficiency by $10-15 \%$ and $17-$ $36 \%$, respectively. Phosphorus and antimony are known to have similar physicochemical properties, since they are both in group VA of the periodic table. It is reasonable to believe that competitive adsorption between phosphate and
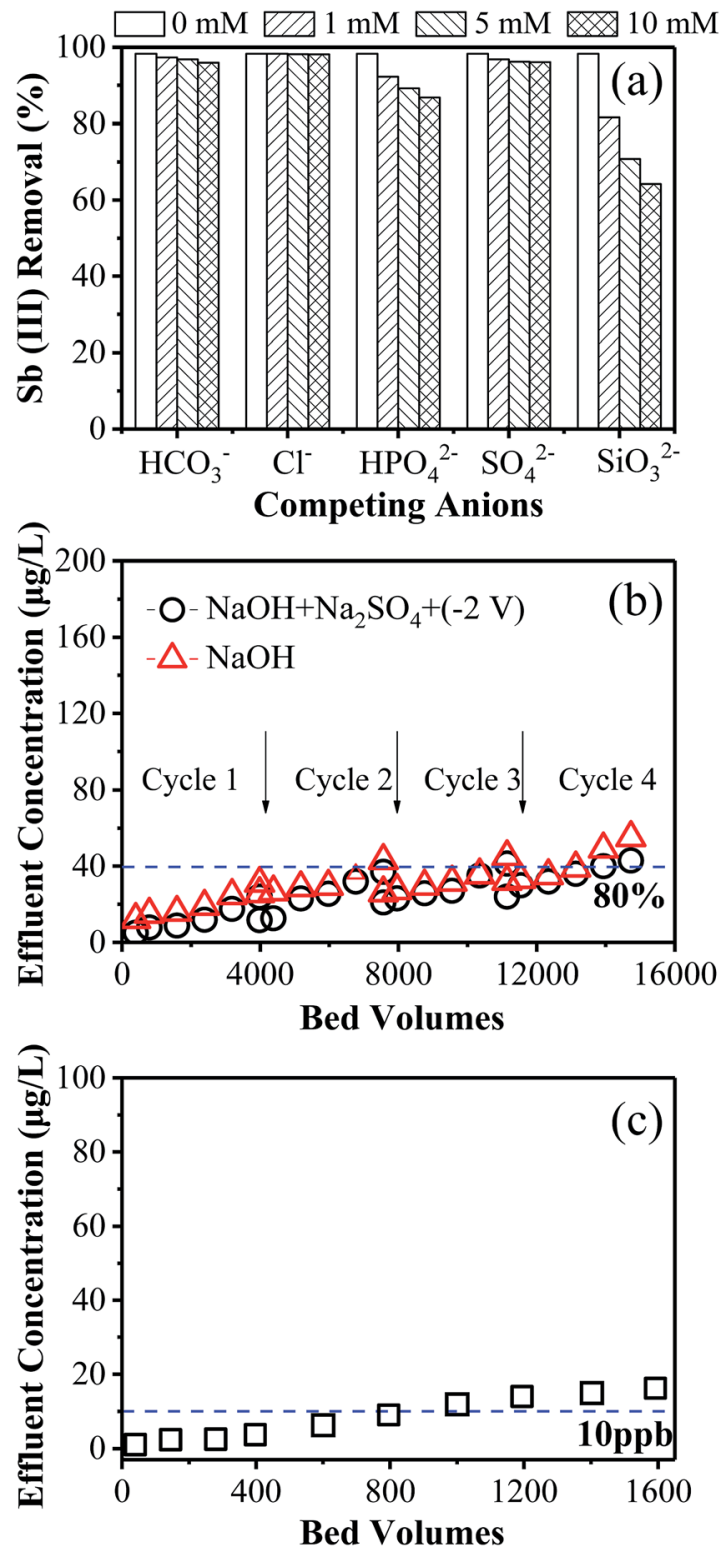

Fig. 5 (a) Effect of competing anions on the adsorption behavior of $\mathrm{Sb}$ (III) on the iron (oxyhydr)oxide/CNT filter. Experimental conditions: $[\mathrm{Sb}(\mathrm{III})]_{\text {in }}$ of $900 \mu \mathrm{g} \mathrm{L}^{-1}$, flow rate of $1.5 \mathrm{~mL} \mathrm{~min}{ }^{-1}, \mathrm{pH}$ of 7 , and recirculation mode. (b) Comparison of two regeneration methods for exhausted iron (oxyhydr)oxide/CNT filters. Experimental conditions:

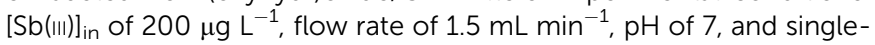
pass filtration mode. (c) Performance of the iron (oxyhydr)oxide/CNT filter when challenged with $\mathrm{Sb}(\mathrm{II})$-spiked tap water. Experiment was conducted in the single-pass filtration mode, $[\mathrm{Sb}(\mathrm{III})]_{\text {in }}$ of $100 \mu \mathrm{g} \mathrm{L}^{-1}$, flow rate of $1.5 \mathrm{~mL} \mathrm{~min}-1$ and $\mathrm{pH}$ of 7 .

$\mathrm{Sb}$ (III) occurred, evidently inhibiting the $\mathrm{Sb}$ (III) uptake performance due to the limited active sites available. ${ }^{30,31}$ Meanwhile, silicate has been reported to be a strongly interfering anion for arsenic (As, a structural analog to $\mathrm{Sb}$ ) adsorption onto iron oxide. ${ }^{32}$ Similarly with $\mathrm{Sb}$, silicate is also inclined to react with metal oxides to form an innersphere complex. ${ }^{33}$ This similar chemisorption mechanism of silicate and $\mathrm{Sb}(\mathrm{III})$ could explain the pronounced 
suppression of $\mathrm{Sb}(\mathrm{III})$ sequestration when compared with other coexisting anions. It is worth noting that the concentration of competing anions is much higher than the actual aquatic conditions, such that the inhibitory effect could be limited in practical applications.

\subsection{Regeneration of exhausted iron (oxyhydr)oxide/CNT filters}

The regeneration of the exhausted iron (oxyhydr)oxide/CNT filter was examined comparatively by either passing through $100 \mathrm{~mL}$ of $5 \mathrm{mM} \mathrm{NaOH}$ solution (i.e., by chemical washing) or applying a negative total cell potential of $-2 \mathrm{~V}$ while passing through $100 \mathrm{~mL}$ of $5 \mathrm{mM} \mathrm{NaOH}$ and $10 \mathrm{mM} \mathrm{Na}_{2} \mathrm{SO}_{4}$ solution (i.e., by chemical washing and electrical repulsion). As shown in Fig. 5b, the regeneration performance of the latter method was always better than that of the former. After three single-pass filtration cycles (i.e., $\sim 11000$ bed volumes), $\mathrm{Sb}$ (III) removal efficiency was still as high as $80.2 \%$ when regenerated using the electrical field-assisted chemical washing method. Such performance dropped slightly to $78.5 \%$ in the fourth cycle. In comparison, a $\mathrm{Sb}(\mathrm{III})$ removal efficiency of $77.1 \%$ was obtained over only two consecutive runs when regenerated by chemical washing alone. This efficiency dropped to $72.5 \%$ in the fourth cycle. The slight increment in $\mathrm{Sb}$ (III) removal caused by the applied electrical field can be ascribed to the electrostatic repulsion of the negatively charged $\mathrm{Sb}(\mathrm{v})$. This indicates that the regeneration of the exhausted iron (oxyhydr)oxide/CNT filter by chemical washing combined with electrostatic repulsion is an effective choice. The optimization of other key operational factors (e.g., applied voltage, flow rate, electrolyte compositions and concentration) require further investigation.

\subsection{Removal performance of $\mathrm{Sb}$ (III)-spiked tap water}

Compared to deionized water, tap water is believed to be more complex as it contains complex salts and organic matters. ${ }^{34}$ To evaluate the practical application potential of the iron (oxyhydr) oxide/CNT filter technology, $100 \mu \mathrm{g} \mathrm{L}^{-1} \mathrm{Sb}$ (III) spiked tap water further challenged the iron (oxyhydr)oxide/CNT filter and was operated in the single-pass operation mode. As shown in Fig. 5c, the iron (oxyhydr)oxide/CNT filter produced 1000 bed volumes of effluent before the removal efficiency of $\mathrm{Sb}(\mathrm{III})$ dropped below $90 \%$. This performance was slightly lower compared with that obtained in the DI- $\mathrm{H}_{2} \mathrm{O}$ matrix, which may be ascribed to the relatively complex composition within the tap water (with a TOC of $\left.2.0 \mathrm{mg} \mathrm{L}^{-1}\right)$. It is to be noted that the hydraulic retention time (HRT) within the filter was only $<2 \mathrm{~s}$ at a flow rate of 1.5 $\mathrm{mL} \min ^{-1}$, which is much lower than the conventional fix-bed filtration with a typical HRT of several minutes or hours. ${ }^{35}$ It can be envisaged that the removal performance could be further increased by further recirculating the effluent. Moreover, negligible iron leaching was detected in the effluent $(<5.2 \mu \mathrm{g}$ $\mathrm{L}^{-1}$ ), implying the desirable stability of the as-fabricated iron
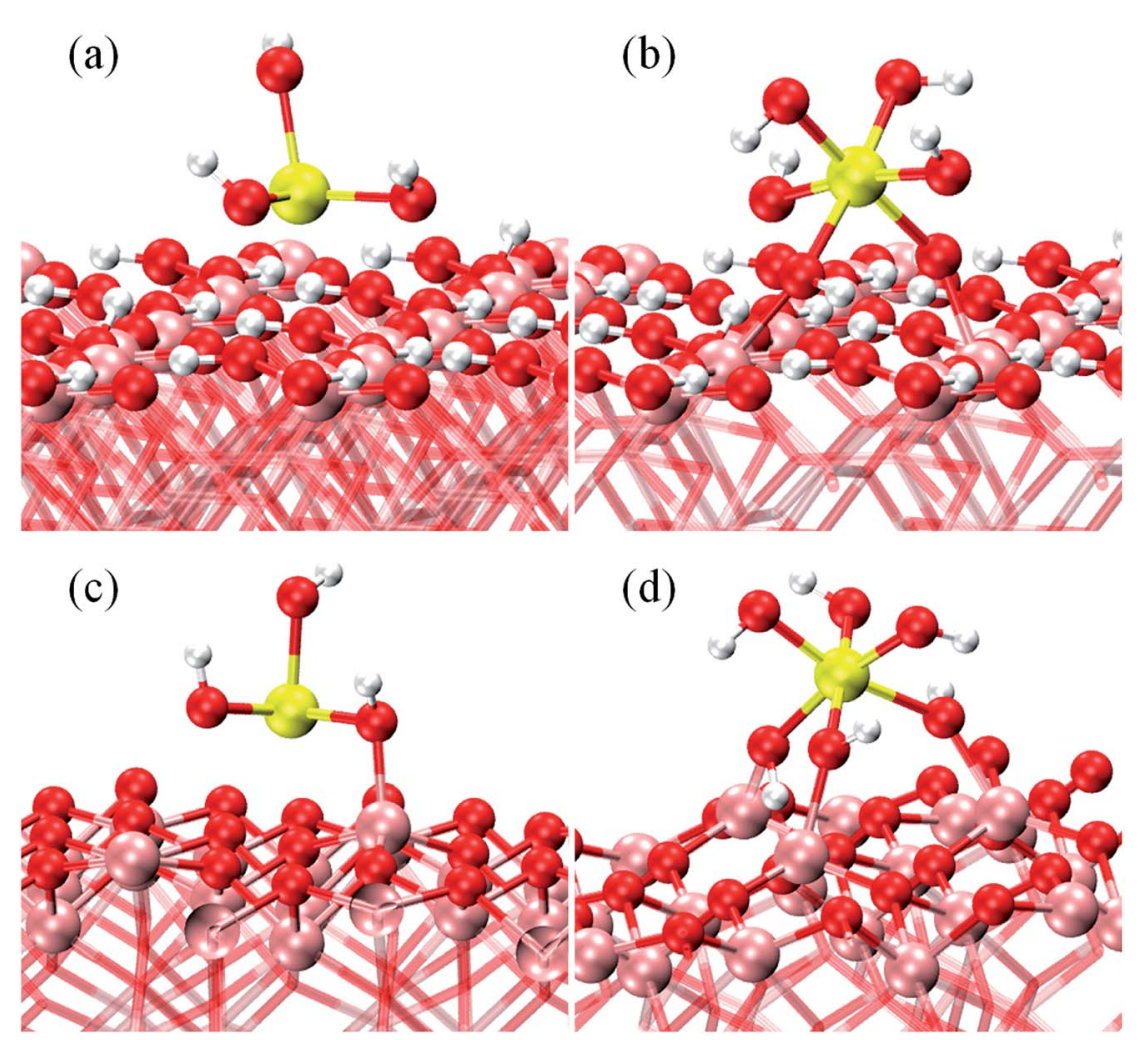

Fig. 6 The optimized adsorption geometries of $\mathrm{Sb}$ (III) on $\mathrm{FeOOH}$ (a), $\mathrm{Sb}(\mathrm{v})$ on $\mathrm{FeOOH}$ (b), $\mathrm{Sb}(\mathrm{II})$ on $\mathrm{Fe}_{2} \mathrm{O}_{3}$ (c), and $\mathrm{Sb}(\mathrm{v})$ on $\mathrm{Fe} \mathrm{O}_{3}$ (d). $\mathrm{Color}$ code: antimony atoms are yellow, oxygen atoms are red, iron atoms are pink and hydrogen atoms are white. 
(oxyhydr)oxide/CNT filter in a continuous-flow filtration process.

\subsection{DFT calculations}

To understand the sequestration mechanism of $\mathrm{Sb}(\mathrm{III})$ and $\mathrm{Sb}(\mathrm{v})$ using the iron (oxyhydr)oxide/CNT filter, DFT calculations were performed to investigate the interaction of $\mathrm{Sb}(\mathrm{OH})_{3}$ and $\mathrm{Sb}(\mathrm{OH})_{6}{ }^{-}$with the iron (oxyhydr)oxides (e.g., $\mathrm{Fe}_{2} \mathrm{O}_{3}$ and FeOOH $)$. A six-layer $(4 \times 4) \mathrm{Fe}_{2} \mathrm{O}_{3}$ facet and a six-layer $\alpha$-FeOOH facet were employed in the simulation. DFT results suggest that the corresponding binding energies for $\mathrm{Sb}$ (III) onto the $\mathrm{FeOOH}$ and $\mathrm{Fe}_{2} \mathrm{O}_{3}$ surfaces were 2.27 and $2.30 \mathrm{eV}$, respectively. In comparison, $\mathrm{Sb}(\mathrm{v})$ could adsorb strongly onto the surfaces of $\mathrm{FeOOH}$ and $\mathrm{Fe}_{2} \mathrm{O}_{3}$ with increased bonding energies of 4.41 and $5.10 \mathrm{eV}$, respectively. The difference in binding energies can be attributed to the different species of $\mathrm{Sb}(\mathrm{III})$ and $\mathrm{Sb}(\mathrm{v})$ in the medium. The negatively-charged $\mathrm{Sb}(\mathrm{v})$ could be anchored strongly onto the positively-charged iron (oxyhydr)oxide via electrostatic attraction, while $\mathrm{Sb}(\mathrm{III})$ is neutrally charged between $\mathrm{pH}$ of 3 to 9 and is not affected by the electrostatic interactions. Moreover, DFT results also indicate that the adsorbed $\mathrm{Sb}(\mathrm{III})$ tends to be oxidized. As suggested by Mulliken charge analysis, the net charge of $\mathrm{Sb}(\mathrm{III})$ increased from 1.08 (before adsorption) to 1.23 when sequestered (by either $\mathrm{FeOOH}$ or $\mathrm{Fe}_{2} \mathrm{O}_{3}$ ). As shown in Fig. 6, $\mathrm{Sb}$ (III) species is not fully coordinated, which enabled $\mathrm{OH}$ from the aqueous phase to oxidize $\mathrm{Sb}(\mathrm{III})$ to $\mathrm{Sb}(\mathrm{v})$. Also, the projected density of states (PDOS, Fig. S10†) suggests that the HOMO-LUMO gap of Sb(III) shrunk significantly from $5.34 \mathrm{eV}$ to $2.57 \mathrm{eV}$ after sorption, which caused $\mathrm{Sb}$ (III) to become more reactive. In contrast, the net charge of $\mathrm{Sb}(\mathrm{v})$ increased from 1.48 to 1.55 on $\mathrm{FeOOH}$ and to 1.59 on $\mathrm{Fe}_{2} \mathrm{O}_{3}$ after adsorption. In other words, when $\mathrm{Sb}$ (III) was adsorbed by $\mathrm{FeOOH}$ or $\mathrm{Fe}_{2} \mathrm{O}_{3}, 0.15$ electrons were imparted to $\mathrm{Sb}(\mathrm{OH})_{3}$ from the surface oxidative layer. Whereas, a slightly weaker charge transfer was observed for $\mathrm{Sb}(\mathrm{v})$, only 0.07 $(\mathrm{FeOOH})$ and $0.11\left(\mathrm{Fe}_{2} \mathrm{O}_{3}\right)$ from the surface to the adsorbed $\mathrm{Sb}(\mathrm{v})$. A similar trend had been reported previously by both experimental and theoretical studies. ${ }^{36-39}$ These DFT results were consistent with the above results of XPS and XAFS characterization and the $\mathrm{Sb}$ valence state analysis of the effluent performed by XAFS.

\section{Conclusions}

A flow-through iron (oxyhydr)oxide/CNT hybrid filter system was developed for rapid and effective sorption removal of $\mathrm{Sb}$ (III) from aqueous solution. Compared to conventional batch system, the proposed filter technology demonstrated enhanced sorption kinetics and capacity. This could be explained by the synergistic effects of flow-through design, convection-enhanced mass transport, limited pore size and more exposed active sites of the filters. Experimental and theoretical evidence suggests that a certain amount of $\mathrm{Sb}$ (III) was converted to $\mathrm{Sb}$ (v) during filtration, which significantly decreased the toxicity of $\mathrm{Sb}$. The proposed filter technology works effectively across a wide $\mathrm{pH}$ range and exhausted iron (oxyhydr)oxide/CNT filters can be effectively regenerated by an electrical field-assisted chemical wash method. Overall, this study provides new insights into the removal of $\mathrm{Sb}(\mathrm{III})$ compounds and other similar toxic heavymetal ions.

\section{Conflicts of interest}

There are no conflicts to declare.

\section{Acknowledgements}

This work was supported by the National Key Research and Development Program of China (No. 2018YFF0215703), the Fundamental Research Funds for the Central Universities (No. 2232019G-11), the Natural Science Foundation of Shanghai, China (No. 18ZR1401000), and the Shanghai Pujiang Program (No. 18PJ1400400).

\section{References}

1 I. Herath, M. Vithanage and J. Bundschuh, Environ. Pollut., 2017, 223, 545-559.

2 M. O. Obiakor, M. Tighe, L. Pereg and S. C. Wilson, Crit. Rev. Environ. Sci. Technol., 2017, 47, 2208-2258.

3 M. Ren, S. Ding, Z. Fu, L. Yang, W. Tang, D. C. W. Tsang, D. Wang and Y. Wang, J. Hazard. Mater., 2018, 367, 427-436.

4 M. He, Environ. Geochem. Health, 2007, 29, 209-219.

5 X. Wang, M. He, J. Xi and X. Lu, Microchem. J., 2011, 97, 4-11. 6 L. Yohai, H. G. Mejia, R. Procaccini, S. Pellice, K. L. Kunjali, J. Dutta and A. Uheida, RSC Adv., 2019, 9, 8280-8289.

7 J. Wang, T. Zhang, M. Li, Y. Yang, P. Lu, P. Ning and Q. Wang, RSC Adv., 2018, 8, 22694-22709.

8 M. Filella, N. Belzile and Y. Chen, Earth-Sci. Rev., 2002, 59, 265-285.

9 N. You, T.-H. Liu, H.-T. Fan and H. Shen, RSC Adv., 2018, 8, 5106-5113.

10 Z. Qi, H. Lan, T. P. Joshi, R. Liu, H. Liu and J. Qu, RSC Adv., 2016, 6, 66990-67001.

11 Z. Wu, M. He, X. Guo and R. Zhou, Sep. Purif. Technol., 2010, 76, 184-190.

12 B. Ma, X. Wang, R. Liu, Z. Qi, W. A. Jefferson, H. Lan, H. Liu and J. Qu, Water Res., 2017, 121, 171-177.

13 B. Ma, X. Wang, R. Liu, W. A. Jefferson, H. Lan, H. Liu and J. Qu, J. Membr. Sci., 2017, 537, 93-100.

14 H. Yang, X. Lu and M. He, Environ. Technol., 2018, 39, 15151521.

15 Y. Liu, P. Wu, F. Liu, F. Li, X. An, J. Liu, Z. Wang, C. Shen and W. Sand, Environ. Sci. Technol., 2019, 53, 1527-1535.

16 G. Li, P. Zhao, H. Zheng, L. Yang, S. Lu and P. Peng, J. Hazard. Mater., 2018, 354, 8-16.

17 J. Wang, Y. Chen, Z. Zhang, Y. Ai, L. Liu, L. Qi, J. Zhou, H. Sun, D. Niu and Q. Liang, ACS Sustainable Chem. Eng., 2018, 6, 12925-12934.

18 X. Guo, Z. Wu, M. He, X. Meng, X. Jin, N. Qiu and J. Zhang, J. Hazard. Mater., 2014, 276, 339-345.

19 B. Lapo, H. Demey, T. Carchi and A. M. Sastre, Polymers, 2019, 11, 351. 
20 A.-K. Leuz, H. Mönch and C. A. Johnson, Environ. Sci. Technol., 2006, 40, 7277-7282.

21 Y. Liu, H. Liu, Z. Zhou, T. Wang, C. N. Ong and C. D. Vecitis, Environ. Sci. Technol., 2015, 49, 7974-7980.

22 Y. Liu, Y. Zheng, B. Du, R. R. Nasaruddin, T. Chen and J. Xie, Ind. Eng. Chem. Res., 2017, 56, 2999-3007.

23 G. Gao, Q. Zhang, Z. Hao and C. D. Vecitis, Environ. Sci. Technol., 2015, 49, 2375-2383.

24 H. S. Yu, X. J. Wei, J. Li, S. Q. Gu, S. Zhang, L. H. Wang, J. Y. Ma, L. N. Li, Q. Gao, R. Si, F. F. Sun, Y. Wang, F. Song, H. J. Xu, X. H. Yu, Y. Zou, J. Q. Wang, Z. Jiang and Y. Y. Huang, Nucl. Sci. Tech., 2015, 26, 7.

25 M. Newville, J. Synchrotron Radiat., 2001, 8, 322-324.

26 J. Hutter, M. Iannuzzi, F. Schiffmann and J. VandeVondele, Wiley Interdiscip. Rev.: Comput. Mol. Sci., 2014, 4, 15-25.

27 L. Yan, J. Song, T. Chan and C. Jing, Environ. Sci. Technol., 2017, 51, 6335-6341.

28 S. Mishra, J. Dwivedi, A. Kumar and N. Sankararamakrishnan, RSC Adv., 2016, 6, 95865-95878.

29 L. Fu, K. Shozugawa and M. Matsuo, J. Environ. Sci., 2018, 73, 31-37.
30 B. Zhang, N. Chen, C. Feng and Z. Zhang, Chem. Eng. J., 2018, 353, 361-372.

31 R. Liu, L. Chi, X. Wang, Y. Wang, Y. Sui, T. Xie and H. Arandiyan, Chem. Eng. J., 2019, 357, 159-168.

32 X. Zhang, M. Wu, H. Dong, H. Li and B. Pan, Environ. Sci. Technol., 2017, 51, 6326-6334.

33 N. V. Tran, A. K. Tieu, H. Zhu, H. T. T. Ta, T. D. Ta and H. M. Le, J. Phys. Chem. C, 2018, 122, 20827-20840.

34 N. Zhang, B. Xu, F. Qi and J. Kumirska, Water Res., 2016, 98, 242-249.

35 Z. He, R. Liu, H. Liu and J. Qu, Environ. Eng. Sci., 2015, 32, 95-102.

36 J. Luo, C. Hu, X. Meng, J. Crittenden, J. Qu and P. Peng, ACS Sustainable Chem. Eng., 2017, 5, 2255-2264.

37 X. Guo, Z. Wu, M. He, X. Meng, X. Jin, N. Qiu and J. Zhang, J. Hazard. Mater., 2014, 276, 339-345.

38 N. Belzile, Y. Chen and Z. Wang, Chem. Geol., 2001, 174, 379387.

39 S. E. Mason, T. P. Trainor and C. J. Goffinet, Comput. Theor. Chem., 2012, 987, 103-111. 